\title{
Quantum crystallography, spectroscopic methods, and hot stage microscopy in the study of chromic multicomponent materials
}

\author{
M. Gryl, M. Kozieł, K. Nowakowska, K.Ostrowska \\ Faculty of Chemistry, Jagiellonian University in Kraków, Gronostajowa 2, 30-387 Kraków, Poland \\ marlena.gryl@uj.edu.pl
}

Solvatochromism, thermochromism and photochromism are just a few examples of phenomena involving stimulated colour change. The external factors influencing absorption can be physical and/or chemical and might lead to variations of materials hue as well as cause limitations of light transmission [1]. Those effects find multiple applications in photochromic lenses, as smart self-dimming windows, paints and indicators, thermal papers, visual displays or biochemical probes. It is of particular interest for those processes to be controllable (selective absorption) and reversible. To achieve this goal it is necessary to gain more knowledge on the origin of those effects.

Recently we have studied (pseudo)polymorphs of tyraminium violurate showing both crystallochromic and solvatochromic effects [2]. We have deduced the origin of colour for each of the three phases using a set of quantum crystallography tools. The fluctuations in the electron density within the oxime group of violurate ions (target) was proven to be one of the factors influencing the absorption. This research forced us to think outside the box and formulate more general guidance criteria on how to design new chromic materials based on a common target molecule (chromogen) and changing selectively co-formers.

In this work, we have engineered a series of chromic materials based on violuric acid and its derivatives. We have chosen co-formers e.g. aromatic, aliphatic amines or pyridine derivatives to obtain a group of distinctly coloured products. The obtained crystal phases were further analysed using UV-vis and NMR spectroscopy as well as XRD and hot stage microscopy.

QTAIM analysis $[3,4]$ in combination with $\mathrm{H}^{1} \mathrm{NMR}$ has enabled us to formulate a more general mechanism of colour generation in the violurate family. The possible phase transitions and influence of the temperature on the colour change in the solid-state were examined using hot stage microscopy and PXRD. The obtained results will contribute to a better understanding of chromic effects in the solid-state as well as in solution. Uncovering the origin of colour in one family of chromogens enables us to influence the absorption of a material by means of cocrystallization.

[1] Bamfield, P., Hutchings, M. (2018) Chromic Phenomena: Technological Applications of Colour Chemistry, Royal Society of Chemistry.

[2] Gryl, M., Rydz, A., Wojnarska, J., Krawczuk, A., Koziel, M., Seidler, T., Ostrowska, K., Marzec, M. \& Stadnicka, K. M. (2019). IUCrJ 6, 226-237.

[3] Bader, R. F. W. (2003). Atoms in Molecules: A Quantum Theory, International Series of Monographs on Chemistry, Vol. 22. Oxford: Clarendon Press.

[4] AIMAll (Version 19.10.12), Todd A. Keith, TK Gristmill Software, Overland Park KS, USA, 2019 (aim.tkgristmill.com)

Keywords: quantum crystallography; crystal engineering; chromic materials; violuric acid

This research was supported by National Science Centre Poland, grant number UMO-2018/30/E/ST5/00638 